\title{
The Application of Mathematical Modeling in Building of Social and Environmental Competence of Future Technical Specialists in the Health Care Area
}

\author{
Elena Chekanushkina ${ }^{1 *}$, Elena Ryabinova ${ }^{1}$, and Diera Pirova ${ }^{1}$ \\ ${ }^{1}$ Samara State Technical University, 443100, Samara, Russia
}

\begin{abstract}
The paper considers building of social and environmental competence of future technical specialists. It shows that health care competence building is becoming more pressing issue each year. Behavioral patterns are formed in the process of training, upbringing and observing people around. They allow forming the ability or readiness to use the acquired interdisciplinary knowledge in professional activities related to health, safety of human life, as well as in the process of studying such disciplines as the "Elective Courses on Physical Education and Sports" and "Physical Education and Sports". The patterns offer the possibility to develop a behavioral socio-ecological algorithm efficiently. In pedagogy and didactic processes, mathematical modeling is aimed at clarifying phenomena that are not amenable to experiment or unobservable as well as patterns of education for the development of efficient teaching technologies. The paper considers mathematical descriptions of the models for formation, interaction and efficiency of various target groups exemplified by Nordic walking, indoor soccer and interdisciplinary teams. It shows the dependence of student group population on an activity and quantitative composition of potential participants of sports group. This mathematical model is also applicable for building socioecological competence of future technical specialists in the framework of participation in interdisciplinary projects, research activities, Olympiads, social and environmental events that contribute to the assimilation of socio-ecological patterns of behavior, the condition for the development of which is the unity of cognitive and practical activities in the process of studying at the university. The paper includes the interim experiment results.
\end{abstract}

\section{Introduction}

Improvement of the life quality and rising life expectancy of every person in our country is declared policy of the Russian Government for the forthcoming years [1,2]. Physical culture and sports are an important part of human activities closely linked to the environment that promote health. The recent problem is building the competences of health care. These competences are directly related to socio-ecological knowledge of future technical specialists. Socioecological knowledge is an integrative set of competencies reflecting the ability and readiness of an individual to perform professional activities and perceive the world around us as the unity of natural and socio-cultural relations. The perception of reality is based on the acquired environmental knowledge, abilities, skills, significant personal and professional qualities and features (motivation, reflection, emotional and volitional capacity, and responsibility). From the perspective of rational use of natural resources and preservation of the environment, a future technical specialist must adequately assess, analyze, forecast and find effective ways to address the tasks set, as well as problems arising from the situation of uncertainty in the interaction between society and nature. Natural, social and environmental factors have a positive effect on the human body and enable harmonious development and health improvement only if a favourable natural environment is preserved from the negative impact of industrial enterprises.

\section{Materials and methods}

The fact of commonness of the laws for the functioning of various objects belonging to different sciences is an essential outcome of the twentieth century. Scientists believe that it is the consequence of solidarity of our world. The synthesis of special sciences result in development of systems theory, information, control, bionics, psychophysics, ergonomics, etc. The synthesis of knowledge in practice brings human activity to the axiomatic level being the highest level of abstraction.

We consider stereotyping of individual behavior provided as a means of relationship with the surrounding world. Instead of inventing new behavioral ways of responding to a particular phenomenon each time, a person uses a

\footnotetext{
* Corresponding author: elenacheka@mail.ru
} 
previously formed model (pattern). The pattern in psychology means a defined set, a sample of behavioral responses or sequences of stereotypical actions.

Various methods for identifying patterns in two-dimensional positional data describing the positions and movements of players in various game sports are considered in domestic and foreign science literature. Mathematical models are developed based on these patterns and they aimed at describing and assessing players' behavior [4,5]. Thus, artificial neural networks are used for analyzing the interaction of teams in handball [6].

The authors of scientific works show that offensive and defensive game schemes can be determined objectively, therefore, the effectiveness of specific tactical activities can be evaluated. Neural networks are also used for strategic planning of the development of physical education and sports, which is necessary to improve the quality of human capital and to ensure the economic security of the country [7].

Scientists are also considering the issue of biomechanical modeling, which is one of the nonlinear methods of identification of parameters for determining the neuromuscular properties of specific knee joint extensor muscles [8]. Thus, the comparison of two mathematical models is made based on ordinary differential equations for simulation of leg stretching experiments.

\section{Results and discussions}

The professional activities of technical specialists influence the environment, and, accordingly, they make an impact on human health 'as far as the environmental factors are the conditions determining the course of those metabolic reactions of the body that a person induces for formation of health' [9]. Behavioral patterns evolve in the process of teaching, upbringing, as well as while observing others. Behavioral models of a technical specialist are associated with building of various competencies. For successful development of the behavioral socio-ecological algorithm, such competences as the ability and readiness to use interdisciplinary knowledge are required. They are based on professional activities in the interests of health, environmental demands and in the study of the following disciplines: "Elective Courses on Physical Education and Sports" (practical studies) and "Physical Education and Sports' (lectures).

The analysis of curricula in technical training areas (21.03.01 Oil and Gas Engineering and 18.03.02 Energy and Resource-Saving Processes in Chemical Engineering, Petrochemistry and Biotechnology) showed that the discipline "Elective Courses on Physical Education and Sports" is taught during six semesters (328 hours). 23 hours per semester are given to students' individual work, and the discipline "Physical Education and Sports" includes four-hour lecture module. Teaching experience clearly demonstrates that introducing the ecological component into these disciplines is viable while building social and environmental competence. Consider the following examples showing the contents of the discipline "Physical Education and Sports" (lectures) (Tables 1, 2).

Table 1. Contents of the module structured by topics (units) specifying the number of academic hours and types of learning sessions.

\begin{tabular}{|c|c|c|c|c|c|c|}
\hline $\begin{array}{l}\text { Unit } \\
\text { No. }\end{array}$ & $\begin{array}{l}\text { Discipline } \\
\text { Name }\end{array}$ & & Type c & our: & oad a & heir \\
\hline \multirow[t]{4}{*}{1} & \multirow{2}{*}{$\begin{array}{l}\text { Impact of } \\
\text { environmental } \\
\text { factors on } \\
\text { health of } \\
\text { students } \\
\text { engaged in } \\
\text { sports and } \\
\text { doing physical } \\
\text { exercises }\end{array}$} & $\mathrm{L}$ & LW & PS & SL & $\begin{array}{l}\text { Total } \\
\text { hours }\end{array}$ \\
\hline & & 2 & - & - & - & 2 \\
\hline & $\begin{array}{c}\text { Preparation for } \\
\text { intermediate } \\
\text { attestation }\end{array}$ & - & - & - & 2 & 2 \\
\hline & Total: & 2 & - & - & 2 & 4 \\
\hline \multicolumn{7}{|c|}{$\begin{array}{c}\text { L-lectures, LW-laboratory work, PS-practical studies, } \\
\text { SL-self learning }\end{array}$} \\
\hline
\end{tabular}

Table 2. Contents of the module lectures

\begin{tabular}{|c|c|c|}
\hline $\begin{array}{c}\text { Unit } \\
\text { No. }\end{array}$ & $\begin{array}{c}\text { Subject of the Lecture and List of } \\
\text { Teaching Units (subthemes and issues } \\
\text { under consideration) }\end{array}$ & $\begin{array}{c}\text { Number } \\
\text { of hours }\end{array}$ \\
\hline \multicolumn{2}{|c}{} \\
\hline
\end{tabular}




\begin{tabular}{|c|c|c|}
\hline 1 & $\begin{array}{c}\text { Topic 1.1. Impact of environmental factors on } \\
\text { health of students engaged in sports and } \\
\text { doing physical exercises. } \\
\text { Environmental approach to physical } \\
\text { education and sports. Environmental health } \\
\text { safety principles. review of environmental } \\
\text { factors and their impact on health and human } \\
\text { life and activities. Classification of } \\
\text { environmental factors. The role of ecological } \\
\text { environment in health care. Motivating } \\
\text { students to nature protection activities. }\end{array}$ & 2 \\
\hline & Total by module: & 2 \\
\hline
\end{tabular}

The working program of the discipline "Elective Courses on Physical Education and Sports" represents self-study tasks that include environmental components for each semester (semesters 1-6). For example, to make a presentation on "Anthropogenic Environmental Factors and Their Impact on the Environment and Human Organism"; to make a bibliographic list on "Influence of Anthropotoxin on the Organisms of Trainees"; to prepare an opinion on the video on "Natural Environment and Human Health"; to develop a set of rules on "Human Interaction with the Environment During Athletic Trainings" and so forth. The working programs of the disciplines indicate the following: a list of teaching and learning materials for preparation for the intermediate attestation; a set of assessment tools for conducting intermediate attestation (a description of indicators, criteria for assessing competence and assessment scales are included); and a list of primary and additional course literature. A list of resources in the information and telecommunication network "Internet" have been defined in the working programs and methodological guidelines for students on studying the contents of the discipline with an environmental component have been developed. More efficient uptake of the abovementioned disciplines is carried out with the use of mathematical modeling.

Mathematical modeling in pedagogy allows analyzing and clarifying the educational phenomena and patterns that are not subject to observation and experiment. This analysis enables the development of new effective teaching technologies. Currently, the significant number of domestic and foreign works are devoted to the problem of teaching processes mathematical modeling [10-15]. In particular, the methods of mathematical modeling relating to the pedagogical experiment (A.E. Upshinskaya), modeling of pedagogical systems (Y.P. Antonov, E.A. Solodova, N.V. Sofronova, R.I. Gorokhova), the use of mathematical models in pedagogy (O.M.Kisileva), and the analysis of the role of mathematical modeling in pedagogical research (I.P. Lebedeva) have been considered.

The articles $[16,17]$ show the appliance of mathematical modeling as a method for forming groups of students with limited health capacities of different nosological forms for practicing Nordic walking that contributes to students' health protection. The novelty of these works is determined by the mathematical description of the models for formation, interaction and performance of various target groups through the example of Nordic walking, indoor soccer and interdisciplinary teams. The correlation between the number of students and the activity and quantitative composition of potential participants of the sports group has been demonstrated.

This mathematical model is relevant to any groups of students.

It is also applicable for building social and environmental competence of future technical specialists that arises in the process of involvement in interdisciplinary projects, research activities, academic olympiads, social and environmental events.

Teams formed with the appliance of the abovementioned mathematical model achieve great success, and the number of students wishing to join this group is increasing. With the use of the applied mathematical model, it is possible to form a group more successfully and to ensure group functioning compared to a group that is formed in a random way. The results of the study have allowed to effectively describe the formation, interaction and performance of sports groups focusing on health care through building social and environmental competences. These mathematical models may be used to describe a wide range of any target groups.

Technological innovations directly relating to building of socio-ecological competence of future technical specialists in the field of health care exist. This is primarily the choice of environmental types of physical activity such as running in parks, swimming in natural reservoirs (rivers, lakes, and others), gymnastics and outdoor games, and so forth. The preference for environmental health care technologies in engagement in sports will give a new boost to the development of eco-tourism, ecological modalities of walking (gymnastics, skiing, various games, and so on). It is evident that the priority shall be given to environmentally friendly clothing. In recent years, a growing number of various accessories and outfits with sensors controlling physical well-being and success of subjects both in a state of rest or motion, training and recovery has been appearing. So, 250 students of Samara State Technical University took part in the study aimed at understanding the role of mobile applications in physical education and ensuring students' healthy lifestyle. More than $50 \%$ of the respondents adhere to a healthy lifestyle, and $30 \%$ responded negatively. Half of the students claim to be physically active people, but just over $40 \%$ do not view themselves as such. $66.7 \%$ of the respondents use various devices for monitoring physical activity. More than $85 \%$ of respondents are familiar with mobile applications for monitoring physical condition and preventing of harmful habits. About $70 \%$ of students believe that such applications are a means of promoting a healthy lifestyle among students. The respondents ranked mobile applications they use. The 
most popular ones are: pedometer, heart rate monitor, calorimeter, and fluid maintenance. Thus, mobile technologies are in active use among the youth and they help to fulfill the rules of healthy lifestyle and adopt the environmental patterns of behavior.

In particular, micro audio players have become widespread: they are convenient and provide access to music at any time and any place, including outdoors. With the help of a "smart" soccer ball, you can automatically detect the crossing of the goal line, and also act as a personal coach for a football player. And, of course, interactive glasses adapted for outdoor sports are widely used.

So, introduction of an ecological component in physical education disciplines, the use of methods of mathematical modeling during class and out-of-class educational activities, innovative technologies in the field of physical education and sports definitely contribute to the effective formation of the social and environmental competence of technical specialists in the process of their studies at a university.

\section{Conclusions}

Thus, development of physical education and sports is an objective and natural process in the life of modern society, directly related to improving the quality and life expectancy of each person. Sports innovations bring additional interest to physical education. Sports activities are becoming easier and more accessible. New opportunities appear for achieving best results in activities related to health care and getting maximum level of pleasure at the same time. Sport is constantly evolving through innovations and does not cease to be in demand in the global community.

Facts and information described in this paper have been studied for the last three years. We plan to publish soon the final results on introduction of the technologies and methods considered above in the educational process aimed at forming of social and environmental competence of future technical specialists.

\section{References}

1. Decree of the President of the Russian Federation of May 7, 2018 No. 204 "On the national goals and strategic objectives of the development of the Russian Federation for the period up to 2024" [Online]. Available: http://press-pubs.uchicago.edu/founders

2. Report by Mikhail Mishustin on the work of the government. URL: https://rg.ru/2020/07/22/otchet-mihaila mishustina-o-rabote-pravitelstva-stenogramma.html.

3. V.N. Mihelkevich, E.N. Chekanushkina, Scientific Journal “Academy bulletin of ELPIT”, 3, 95-100 (2019)

4. M. Huang, Y Lin, Regression Symmetry, 12, 835 (2020). DOI: 10.3390/sym12050835

5. G. Budak, İ. Kara, et al. Research, 27, 93-109 (2019). DOI: 10.1007/s10100-017-0491-X

6. S. Alsaied, A. Hasaan, N. Schrapf, Analysis of Interaction Between Offense and Defence Tactics in Team Handball by Means of Artificial Neural Networks in Mathematical and computer modelling of dynamical systems, 23(4), 363-371 (2015). DOI: 10.1080/13873954.2017.1336733

7. E. Letiagina, V. Perova, Elena Orlova, Neural network analysis of the development of physical education and sports in Russia as an economic factor of country security in 4th International Conference on Innovations in Sports, Tourism and Instructional Science (ICISTIS 2019), 138-142 (2019)

8. A. Baca, Mathematical modelling in sport and human movement science in Mathematical and Computer Modelling of Dynamical Systems, 23(4), 361-362 (2017), DOI: 10.1080/13873954.2017.1336636

9. E.P. Plotnikova, Science and education Bulletin, 17(53), 46-48 (2018)

10. P. Atkinson, Introduction to mathematical learning theory, 1487 (1969)

11. V.P. Bespalko, Lectures on Nontraditional Pedagogy (Human education, M., 2008)

12. L.B. Itelson, Mathematical and cybernetic methods in pedagogy (Pedagogics, M., 1964)

13. S.A. Piyavsky, Journal of Computer and Systems Sciences, 3, 100-106 (2000)

14. M.I. Poteev, Fundamentals of Analytical Didactics (LITMO, SPb., 1992)

15. E.N. Ryabinova, Adaptive system of personalized professional training of students of technical universities (Engineering, M., 2009)

16. D.F. Pirova, Papers of the International Science and Practice Conference (Cheboksary, 469-471, 2019)

17. D.F. Pirova, Papers of the International Scientific and Technical Conference convened to mark the centenary of the Republic of Bashkortostan (UGNTU, Ufa, 363-364, 2019) 